\title{
Agricultural Tile Drainage Detection within the Year Using Ground Penetrating Radar
}

\author{
Petr Karásek ${ }^{1 *}$, Eva Nováková \\ 1 Research Institute for Soil and Water Conservation, v.v.i., Department of Land Consolidations and Land Use \\ Planning, Lidická 25/27, 60200 Brno, Czech Republic \\ * Corresponding author's e-mail: karasek.petr@vumop.cz
}

\begin{abstract}
The aim of this study was to identify the tile drainage systems within the year (from spring to autumn) using the ground penetrating radar (GPR) geophysical method. The measurements were performed in the experimental locality Dehtáře in the Bohemo-Moravian Highland (Czech Republic) in the years 2016 and 2017. The profiles located in the drained area were repeatedly measured together with the drainage discharges, soil moisture and groundwater level. The best visibility of tile drains was observed during snowmelt (in March and April) when the drainage discharges usually reach their maximum. In other months, the visibility of the drains was variable, but mostly worse. For a reliable detection of individual drains, the measurements above the drainage must be performed in several profiles. Under the conditions of the Czech Republic, the best results were obtained by a $500 \mathrm{MHz}$ frequency antenna.
\end{abstract}

Keywords: tile drainage detection; tile drain;ground penetrating radar(GPR);geophysical method;soil amelioration

\section{INTRODUCTION}

The tile drainage, as a common agricultural tool for improving soil characteristics, was very popular in the 20th century. More than 1,065 million ha of soil were drained, which represents approximately one fourth of the agricultural land in the Czech Republic (Kulhavý et al., 2007; Karásek et al., 2015). Recently, no new drainage systems have been built because the attitude towards and social demand for intensive agricultural exploitation of land have changed. However, many areas experience the problems connected with the ageing of the drainage systems. Large parts of the documentation recording the spatial distribution of draining systems have been lost or do not correspond to the real situation. Therefore, there is a demand for a precise identification of the drainage systems directly in the field.

Since the drainage systems mostly consist of pipes under the ground level, various geophysical methods are used for their localization (Allred et al., 2004). The Ground Penetrating Radar method
(GPR) has been used for the identification of the agricultural drainage systems worldwide since the 1990s. Most interest has been devoted to this method in the USA. Allred and Daniels (2008) assessed the ability of the geo-radar to detect the agricultural drainage in 14 localities in the Midwest. The area of the tested localities ranged between 200-12000 $\mathrm{m}^{2}$ and differed in soil texture. These authors evaluated the effect of the antenna frequency $(100,250$ and $500 \mathrm{MHz})$, soil hydrological conditions, construction material of the drainage, and drainage orientation. Using GPR, Allred and Redman (2010) were able to evaluate the condition of the draining pipes including the identification of the obstruction places. The drainage pipes were also investigated using GPR, e.g. by Sheng-Huoo et al. (2010) and Ayala-Cabrera et al. (2011).

The aim of this study was to test the GPR potential for identifying the tile drains in the course of different seasons under the conditions of the Czech Republic, where the drain tiles have usually smaller diameters than in the USA. 


\section{MATERIAL AND METHODS}

\section{Ground Penetrating Radar}

The GPR method is based on measuring the travel time of electromagnetic pulse that was emitted by the transmitting antenna to the subsurface. The electromagnetic pulse is partly reflected from the interface and from the objects lying under the ground level and returns to the surface, where it is received by the receiving antenna(Annan, 2002; Allred et al., 2008). The depth of the signal penetration and the resolution are influenced by the antenna frequency as well as the factors related to the electric conductivity and permittivity of the studied environment such as moisture, texture (clay content) and salinity. At lower frequency, the depth of the signal penetration increases but the resolution decreases, and vice versa. The higher the soil conductivity, the lower the signal penetration. For instance, using $1 \mathrm{GHz}$ frequency, several $\mathrm{cm}$ resolution can be obtained (only to a small depth of around $0.25 \mathrm{~m}$ ), while using the antenna frequency of $10 \mathrm{MHz}$, the depth of $10 \mathrm{~m}$ can be reached, but with $1 \mathrm{~m}$ resolution. The details about the GPR method can be found, e.g. in van der Kruk et al. (1999), Jol (2009).

During the investigation of the drainage systems, the signal moves in three different environments, which play an essential role in the detection of these systems: soil surrounding the pipes, water running in the pipes and air inside the pipes. The relative permittivity (permittivity of material/permittivity of free space or vacuum) represents another factor influencing the quality of the signal. The relative permittivity of air is around 1 , its value for water is 80 , for the dry soil it is 5 to 15 , and for the very humid soil - about 30 to 40 (Daniels, 2004). The combination and sharpness of these three environments determines the quality and quantity of the resulting reflection image on the GPR radargram. The material of the pipes does not play any significant role, as found by Allred and Daniels (2004).

\section{Study area}

The investigation was conducted in the experimental locality Dehtáre in the south-west part of Bohemo-Moravian Highland, in the tile drainage system extending over 19 ha. The area of catchment falling into the drainage system is 59.6 ha. The altitude ranges between 497.0 and $549.8 \mathrm{~m}$ a.s.l. The systematic tile drainage was built in 1977 in the discharge zone of the catchment (described in detail by Kvítek, 1985; Zajíček et al., 2011). It consists of several drainage subsystems and their intercepting drains, which partially catch the water inflow from the upslope areas of the watershed. The spacing of the drains is 13 or $20 \mathrm{~m}$; their depth is about 1.0 and $1.1 \mathrm{~m}$. The tiles are made from clay with the diameter varying from 4.5 to $10 \mathrm{~cm}$. The drainage discharges are measured continuously with 10-minute recording. For the purpose of this paper, the data from two drainage subsystems were evaluated. The KP subsystem (measured in the manhole with the same name) receives the water drained from the entire right (northern) part of the drainage system with an area of 28.6 ha. The K1 subsystem with its intercepting drain tile $-\mathrm{K} 2$ (K1, $\mathrm{K} 2$ manholes) - collects water from 1 ha drainage area with 2.4 ha recharge area. The level of groundwater table is measured in the boreholes located next to the drainage system. Three of the boreholes are equipped with an automatic gauge and record measurements by pressure transducers LMP 307 (BD SENSORS, Czech Republic) at 1-h intervals. These boreholes were designated HV2, HV4, and HV8 (Figure 1) and their depth was 2,4 , and $8 \mathrm{~m}$, respectively. In the three other boreholes that were $3 \mathrm{~m}$ deep (V11 - V13), the measurements were performed manually every two weeks.

According to the World Reference Base for soil resources (WRB) 2006, the main soil types are Haplic Cambisols in the recharge zone of the area and Stagnic Cambisols and Haplic Stagnosols in the discharge zone, with small areas of Haplic Gleysol and Fibric Histosol, varying in texture from silty-loam and loam in the discharge zone to sandy-loam and loamy-sand in the recharge zone.

The GPR measurements were performed mainly in the lower part of the drainage system. This area is completely grassed and repeated measurements could be performed within the entire year. The measurement and movement in the arable land was limited by the stage of the crop and ploughing. In 2016, repeated measurements were performed in plot A and in 2017, the measurements were performed in the precise net of regular parallel 5-m-spaced transects vertical to the tile drains (plots A1 and B). These transects were delineated using a length gauge and GPS location. In our project, the RAMAC GPR 


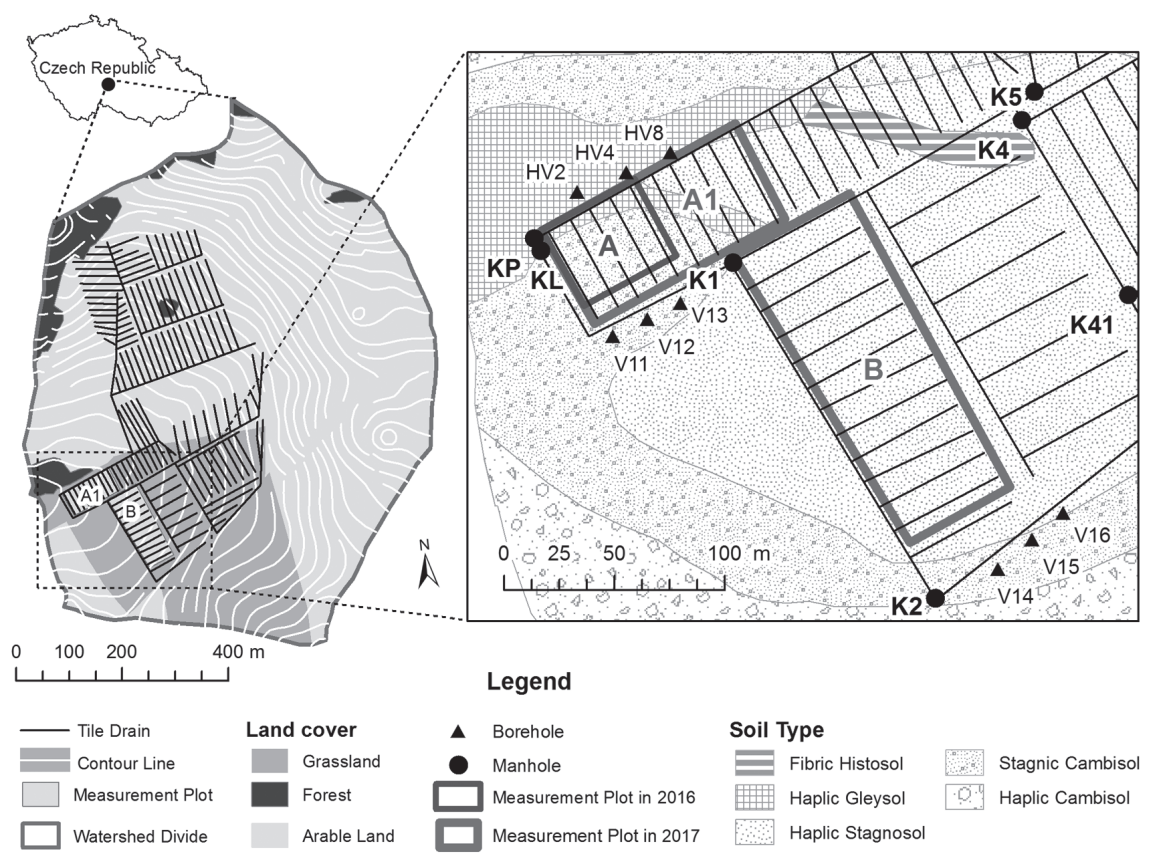

Fig. 1. Location and overview of the experimental area

equipment (Malå GeoScience, Sweden) was used with shaded antennas transmitting the central frequency of 250 and $500 \mathrm{MHz}$. For data collection the authors used the reflection method of survey named Single-Fold Common-Offset. The antennas were firmly fixed at a particular distance and the data collection was done by continuously dragging the antennas on the earth surface. The distance was measured by a survey wheel towed behind the antenna. The data obtained were then processed using the REFLEXW program (Sandmeier Software, Germany).

The discharges in manholes, the level of groundwater table (GWT) in the boreholes and the soil moisture content in manhole $\mathrm{K} 1$ in the depth of $100 \mathrm{~cm}$ were monitored as complementing data (using ThetaProbe ML2x sensors from Delta-T Devices, UK).

\section{RESULTS}

\section{Selection of antenna}

The antennas with 250 and $500 \mathrm{MHz}$ frequency with varying default parameters were used for measurements. Under the conditions of the Czech Republic, the best performance was shown by the antenna of $500 \mathrm{MHz}$ frequency, which was capable of reaching the required depth of the drain tile. This antenna also provided better resolution than the $250 \mathrm{MHz}$ antenna. The comparison of results from the same transect monitored with both antennas is shown in Figure 2. The default parameters for further GPR measurements were: step $0.03 \mathrm{~m}$, stack 16 , time window $60 \mathrm{~ns}$.

The reflection from an object (drain tile) is usually seen as a hyperbola of varying intensity and quality (Fig. 3). A similar reflection, however, may also originate from an object other than the tile, e.g. a stone. Such false reflection is seen in Figure $3 \mathrm{a}$ at a distance of $21 \mathrm{~cm}$. In order to ensure that the radar reflection truly shows the investigated drain tile, it should be identified in at least three transects in the expected distance and depth. This verification can exclude other false reflections.

\section{Year 2016}

In 2016, the authors performed repeated measurements in five days in the selected plot A throughout the growing season. The measurement days were chosen irregularly to capture different soil conditions. The resulting tile drain visibility, as defined by tile identification on the radargrams, is shown in Figure 4.

In April, the tile drains were easily found on the radargrams. In May, although only two weeks later, the quality of the radargram decreased. In other months, individual tiles could be identified, but in fewer locations. The quality of reflections 


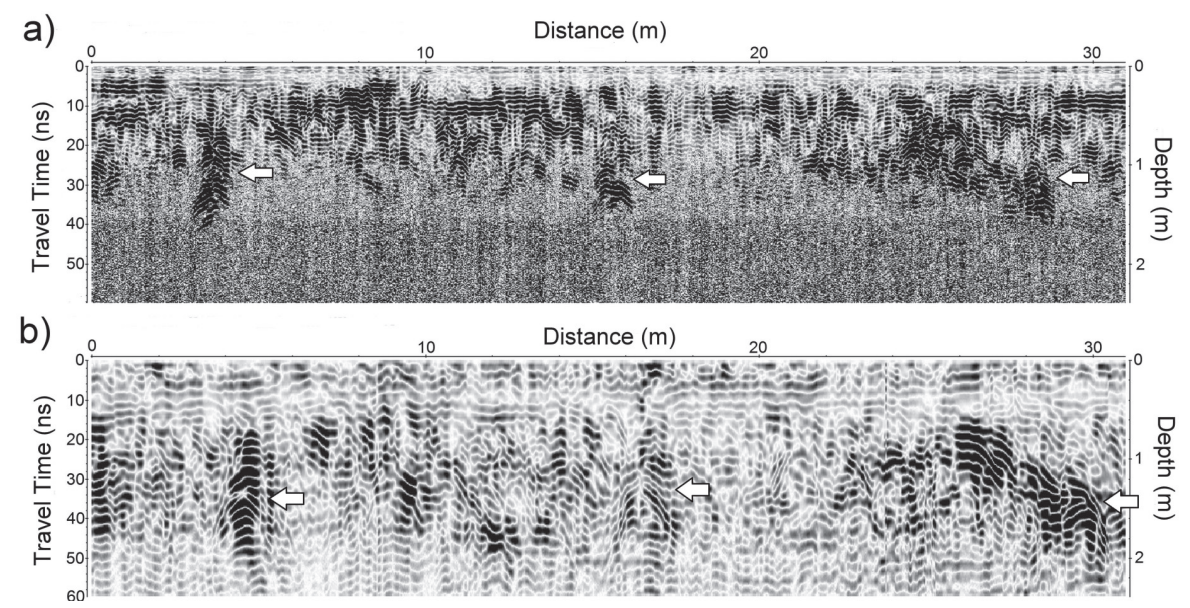

Fig. 2.Ground penetrating radar (GPR) profiles obtained with a) $500 \mathrm{MHz}$

b) $250 \mathrm{MHz}$ antenna with reflections of three drain tiles marked by arrows

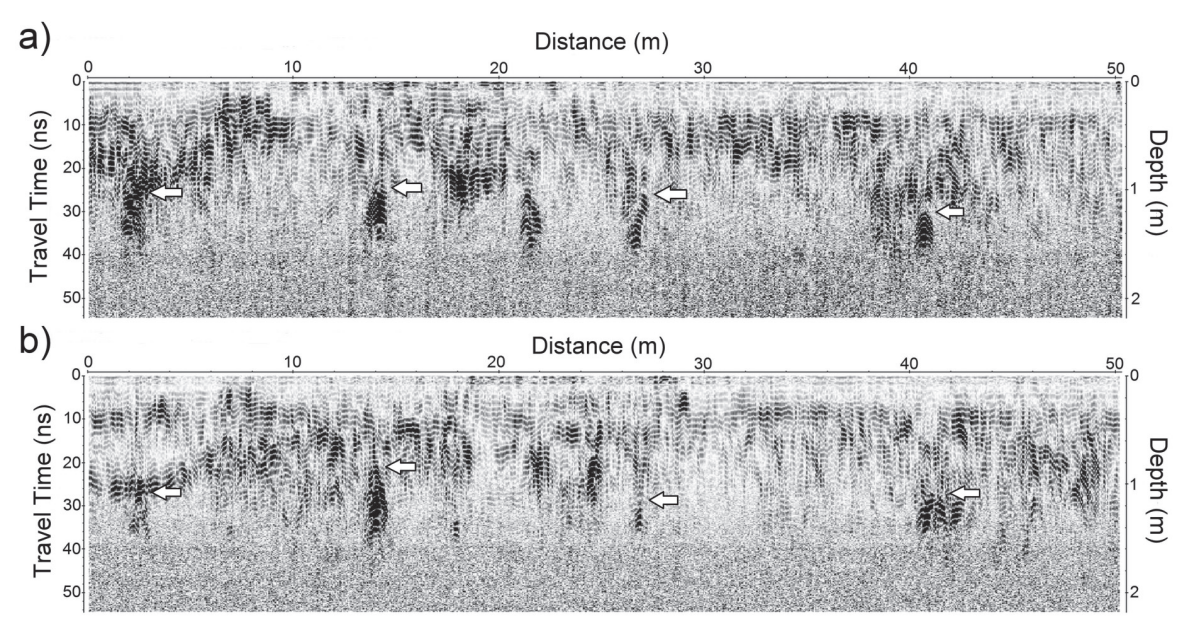

Fig. 3. Example of drain tile images on the GPR radargram - two parallel profiles following one after the other and four drain tiles marked by arrowheads
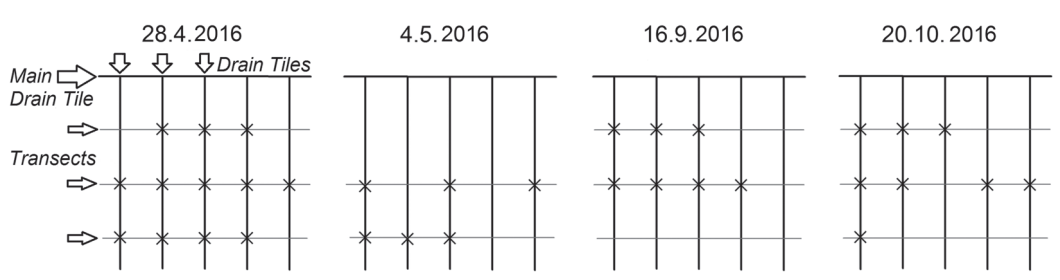

24.11. 2016

Fig. 4. Schematic representation of the tile drain visibility in plot A in 2016 (crossesdenotethe visible tiles in the GPR radargram)

of the signal on the radargrams was weak. Table 1 shows the visibility of tile drains, i.e. the percentage of drains identified in the radargrams out of the number expected during the measurements. Due to the different numbers of the transects investigated in different days, this value is only indicative. The effectiveness of the measurement and further supplementary data are presented in Tab. 1 and Tab. 2.
The data on the groundwater level have a critical role. Since the position of the drains is not planar but slightly sloping, the height of GWL in plot A has to be correlated from the data of the boreholes HV2-8 and V11-V13. GWL in the HV2-8 boreholes fluctuated around $0.5-0.6 \mathrm{~m}$ under the surface on all measurement days, while in the V11-V13 boreholes in spring months it oscillated around $0.8 \mathrm{~m}$. All drain tiles were definitely 
Table 1. Data of measurement days - percentage of visibility of (identified) tile drains,flowrates inmanholes(Q) andaverage groundwater level (GWL) in individual borehole groups in2016

\begin{tabular}{|c|c|c|c|c|c|c|c|c|}
\hline \multirow{2}{*}{ Date of measurement } & \multirow{2}{*}{ Plot } & Drain visibility & \multicolumn{3}{|c|}{$\mathrm{Q}(\mathrm{I} / \mathrm{s})$} & \multicolumn{3}{c|}{ GWL $(\mathrm{m})$} \\
\cline { 3 - 10 } & & $\%$ & $\mathrm{KP}$ & $\mathrm{K} 1$ & $\mathrm{~K} 2$ & $\mathrm{HV} 2-\mathrm{HV} 8$ & $\mathrm{~V} 11-13$ & $\mathrm{~V} 14-\mathrm{V} 16$ \\
\hline 28.04 .2016 & $\mathrm{~A}$ & 80 & 0,82 & 0,12 & 0,1 & 0,49 & 0,77 & 1,2 \\
\hline 04.05 .2016 & $\mathrm{~A}$ & 60 & 0,71 & 0,12 & 0,11 & 0,52 & 0,8 & 1,23 \\
\hline 16.09 .2016 & $\mathrm{~A}$ & 47 & 0,6 & 0,17 & 0,03 & 0,59 & 0,97 & 1,6 \\
\hline 20.10 .2016 & $\mathrm{~A}$ & 53 & 0,76 & 0,03 & 0,05 & 0,55 & 0,98 & 1,62 \\
\hline 24.11 .2016 & $\mathrm{~A}$ & 40 & 0,55 & 0,03 & 0,04 & 0,59 & 1,04 & 1,66 \\
\hline
\end{tabular}

Table 2. Soil moisture (\%) in manholes $\mathrm{K} 1$ and $\mathrm{K} 2$ at various depths in 2016

\begin{tabular}{|c|c|c|c|c|c|c|}
\hline \multirow{2}{*}{ Date of measurement } & \multicolumn{3}{|c|}{ K1 } & \multicolumn{3}{|c|}{$\mathrm{K} 2$} \\
\hline & $30 \mathrm{~cm}$ & $60 \mathrm{~cm}$ & $100 \mathrm{~cm}$ & $30 \mathrm{~cm}$ & $60 \mathrm{~cm}$ & $100 \mathrm{~cm}$ \\
\hline 28.04 .2016 & 31,1 & 31,3 & 30,8 & 23,8 & 20,7 & 19,6 \\
\hline 04.05 .2016 & 30,5 & 31,3 & 30,8 & 23,2 & 20,4 & 19,5 \\
\hline 16.09.2016 & 31,2 & 30,9 & 30,7 & 23,9 & 19,3 & 18,9 \\
\hline 20.10 .2016 & 30,6 & 30,9 & 30,7 & 24,1 & 19,3 & 18,7 \\
\hline 24.11 .2016 & 30,8 & 30,3 & 30,6 & 24 & 19,3 & 18,6 \\
\hline
\end{tabular}

under GWL. In the autumn months, GWL in the V11-V13 boreholes oscillated around $1 \mathrm{~m}$. The extremities of the collecting drains could therefore be above GWL. However, there is a high probability that most drains were under GWL.

The soil moisture measured in the K1 manhole, which is located approximately at the level of the V11-V13 boreholes, was nearly the same in the depth of $100 \mathrm{~cm}$, slightly decreasing from 30.8 to $30.6 \%$ in the course of the year. At the depth of $60 \mathrm{~cm}$, it fluctuated between 31.3 and $30.3 \%$, and at the depth of $30 \mathrm{~cm}$ between 31.1 and $30.8 \%$.

Indicative information on the tile drain discharges from plot A can be obtained from the data recorded in the KP manhole. The indicative nature of this information is due to the fact that the KP manhole receives water from the entire system in the upper north-west part of the catchment. However, based on these data it may be concluded that on all measurement days, there was discharge from the plot A.

\section{Year 2017}

In 2017, the authors performed measurements on three days, each representing a different season - spring, summer and autumn. In April, the visibility of tile drains in radargrams was relatively good in the plot A1, and only one drain was identified just once (Figure 5). Other tile drains were visible in at least four profiles. In July, the results were completely different. The drains were mostly visible in the GPR radargrams of one transect only; the last three drains were not visible at all. In November, the visibility of tile drains in radargrams improved and was comparable to or better than in April.

In April, the visibility of tile drains in Plot B (Fig.6) was good in the upper part of the schematic drawing. In the second half of the plot, only about half the length of the tile drains was visible, more distally from the mouth of the main drain. In July, only the first four drains (close to the K1 manhole) could be identified in the plot. The others were visible only sporadically. In November, the visibility was as good as in April. The last four tile drains were not investigated.

When the visibility of tile drains is transferred to percentage, the data are following: in April the success rate in tile drain identification in plot A1 was $52 \%$ and in plot B $-65 \%$. In July, the success rate dropped significantly. In plot A1, only $10 \%$ of possible tile drains were identified; in plot B, the success rate was $30 \%$. In November, the identification was more successful again and reached $57 \%$ in plot $\mathrm{A} 1$ and $78 \%$ in plot B. The effectiveness of measurements and further supplementing data are presented in Table 3 and Table 4.

Figure 7 shows a part of plot $B$ with four drain tiles, which was investigated in April by measurements in 20-cm transects. The high density of the investigated transects allowed the $3 \mathrm{D}$ processing of the radargrams from these measurements. A cross-section from the depth of 34 ns is shown. 


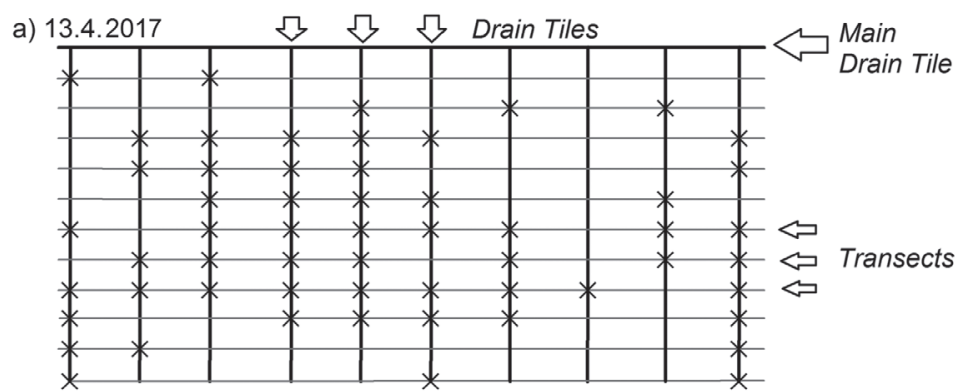

b) 10.7 .2017

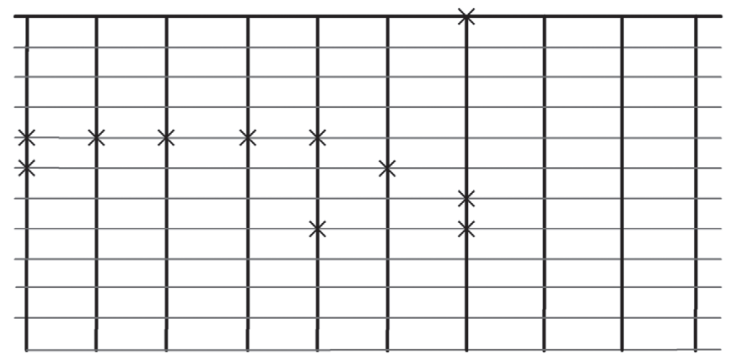

c) 22.11 .2017

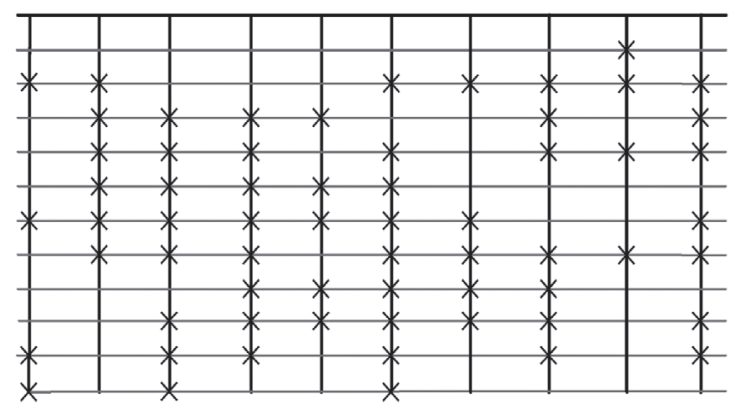

Fig. 5.Schematic representation of the tile drain visibility in plot A1 a) April 2017; b) July 2017, c) November 2017 (crossesdenotethe visible tiles in GPR radargram)

a) 13.4 .2017

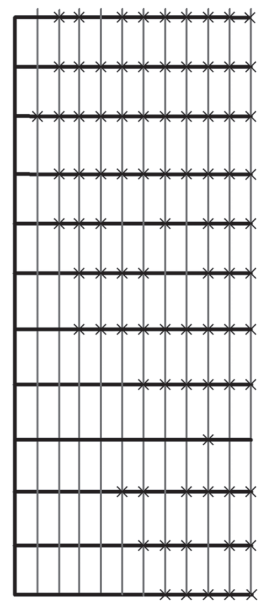

b) 10.7 .2017

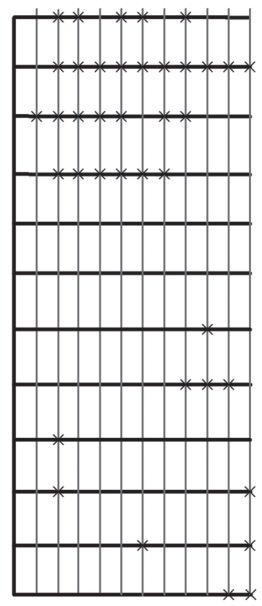

C) 22.11 .2017

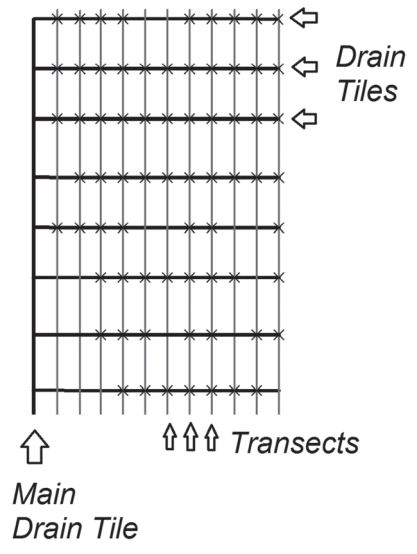

Fig.6. Schematic representation of the spatial tile drain visibility in plot B. a) April 2017; b) July 2017 c) November 2017, the last four tile drains were not investigated (crossesdenotethe visible tiles in GPR radargram)

In April 2017, the groundwater level in the HV2-8 boreholes fluctuated around $0.4 \mathrm{~m}$. July was a dry period and the level dropped down to $0.8 \mathrm{~m}$. In November, it rose again to $0.6 \mathrm{~m}$. The groundwater level in the V11-V13 boreholes in April was $0.6 \mathrm{~m}$. The drain tiles in plot A were therefore situated under the groundwater level. In July, the GWL dropped down to $1.3 \mathrm{~m}$ and in 
Table 3. Data of measurement days - percentage of visibility of (identified) tile drains, flowrates in manholes (Q) and average groundwater level (GWL) in individual borehole groups in2017

\begin{tabular}{|c|c|c|c|c|c|c|c|c|}
\hline \multirow{2}{*}{$\begin{array}{c}\text { Date of } \\
\text { measurement }\end{array}$} & \multirow{2}{*}{ Plot } & Drain visibility & \multicolumn{3}{|c|}{$\mathrm{Q}(\mathrm{I} / \mathrm{s})$} & \multicolumn{3}{c|}{$\mathrm{GWL}(\mathrm{m})$} \\
\cline { 3 - 9 } & & $\%$ & $\mathrm{KP}$ & $\mathrm{K} 1$ & $\mathrm{~K} 2$ & HV2-HV8 & V11-13 & V14-V16 \\
\hline 13.04 .2017 & $\mathrm{~A} 1, \mathrm{~B}$ & 52,65 & 1,33 & 0,08 & 0,1 & 0,4 & 0,61 & 1,22 \\
\hline 10.07 .2017 & $\mathrm{~A} 1, \mathrm{~B}$ & 10,30 & 0,2 & 0,18 & 0,03 & 0,81 & 1,3 & 1,7 \\
\hline 22.11 .2017 & $\mathrm{~A} 1, \mathrm{~B}$ & 57,78 & 0,15 & 0,02 & 0,03 & 0,64 & 1,2 & 1,82 \\
\hline
\end{tabular}

Table 4. Soil moisture (\%) in the K1 and K2 manholes at various depths in 2017

\begin{tabular}{|c|c|c|c|c|c|c|}
\hline \multirow{2}{*}{ Date of measurement } & \multicolumn{3}{|c|}{$\mathrm{K} 1$} & \multicolumn{2}{c|}{ K2 } \\
\cline { 2 - 6 } & $30 \mathrm{~cm}$ & $60 \mathrm{~cm}$ & $100 \mathrm{~cm}$ & $30 \mathrm{~cm}$ & $60 \mathrm{~cm}$ & $100 \mathrm{~cm}$ \\
\hline 13.04 .2017 & 31,8 & 30,5 & 30,6 & 25,4 & 21,5 & 20,1 \\
\hline 10.07 .2017 & 15,7 & 28,9 & 29,2 & 19,1 & 16,2 & 18,5 \\
\hline 22.11 .2017 & 31,1 & 29,1 & 30,1 & 23,3 & 14,1 & 17,3 \\
\hline
\end{tabular}

November it returned just to $1.2 \mathrm{~m}$. These data show that in July, most tile drains were above GWL, almost certainly without any flow. This is also confirmed by the low flow rate in the KP manhole. In November, the lower part of the tile drains (namely close to the main drain tile of the boreholes HV2-8) was under water, but according to the flow rate in KP, the discharge from the drains was very low or none.

Assessment of the data on the oscillating GWL in plot B requires the records from the V14V16 boreholes. In April, the GWL was $1.2 \mathrm{~m}$ and in July it dropped to the depth of $1.7 \mathrm{~m}$. This drop continued throughout November to $1.8 \mathrm{~m}$. By interpolating these records with the data from the V11-V13 boreholes it was found that in April, the major part of tile drains were probably under the GWL. Some drain tiles close to the V14V15 boreholes could already be above GWL. Concerning July and November, it may almost certainly be concluded that the groundwater level was under the drain tiles.

The information on the flow rates in the drain tiles in this plot is obtained from the measurements of flow rates in the K1 and K2 manholes. The K2 manhole receives water from the intercepting drain deposited at a depth of $1.6 \mathrm{~m}$, and the K1 manhole thus collects water not only from collecting drains and from the drainage system of study plot B, but also from this intercepting drain. In the intercepting drain, water is running throughout the year and it may be expected that when the flow rate recorded in the K2 manhole is higher than that in the $\mathrm{K} 1$ profile, the collecting drains of the drainage system (subject to radar investigation) do not contain any water. According to this hypothesis, the flow in conducting drains of this plot is not continuous in the course of the year. Having available data on the flow rates in the manholes for several years,

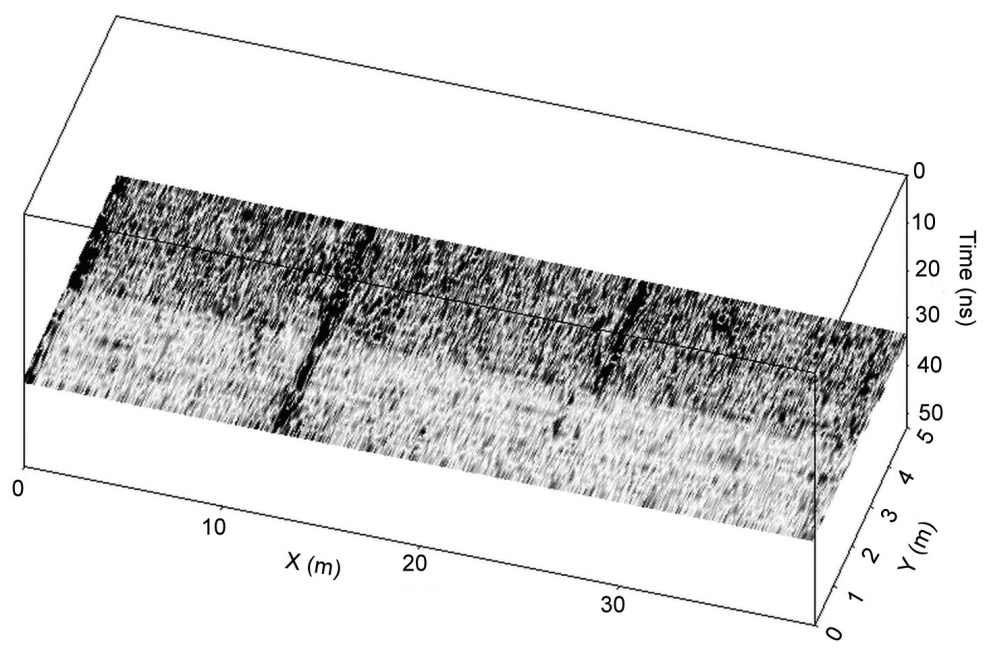

Fig. 7. Image of a slice of record processed in 3D imaging at time $34 \mathrm{~ns}$ with four drain tiles 
the authors were able to assess the flow trend for this part of the drainage system under plot B in the course of the year.

The stable but mostly very low flow rate in the drain tiles during the winter is followed by a marked increase during snowmelt; the flow rate then decreases and depending on the water abundance of the particular year, the flow in conducting drains, namely in higher situated parts of the locality, even stops completely. In the period of the investigated visibility, i.e. the hydrological year 2017, the flow rate in the investigated tile drains displayed a similar course. With high probability, the drains contained water in the autumn, namely in the period 10.11. $2016-6.12 .2016$ (with, however, very low discharge), and then since 26. 12. 2016 until 21.3. 2017, with the exception of the period 13.2.-27.2. This period also marked two significant discharge elevations in the first half of January during partial snowmelt and starting from the end of February, during the spring snowmelt. In the warm period of the year, the flow rate gradually decreased and from the end of May to the end of September(except for some rainfall-runoff events), there was probably no discharge at all. A single rainfall-runoff event took place a day before measurement in July 2017. That is why on 10.7.2017, a relatively high flow rate was recorded in $\mathrm{K} 1$.

The recorded moistures shown in Tables 2 and 4 illustrate the drop of values at all depths, both in K1 and K2. In November, the moisture in $\mathrm{K} 1$ again increased at all levels, in accord with GWL restoration. In the $\mathrm{K} 2$ manhole, the moisture increased only at $30 \mathrm{~cm}$ depth. In contrast, at 60 and $100 \mathrm{~cm}$ the moisture even decreased. This corresponds to the fact that GWL in this locality dropped again in November.

\section{DISCUSSION}

Allred and Daniels (2008) reported that drains are best identified by GPR when the drain tiles contain air and the surrounding soil is moist (the permittivity contrast is maximal). Conversely, the poorest results are obtained when the soil is moist and the tiles are filled with water. It means that in theory, the best reflection should be observed when the drain tiles are under GWL (highest soil moisture) and the drain tiles air-filled. This is in accordance with our finding that most drain tiles were identified in spring. In this period, GWL was above the level of drain tiles in the tested plots and the soil contained the maximum moisture. In plot A (A1), the flow rates were probably the highest, while in plot $\mathrm{B}$ the discharge had already stopped or was very low. It means that the air content is the decisive factor, rather than the quantity of water running through the drain tile. When the drain tile is partly or completely filled with water, there are no reflections. That is why the identification of drains in the transect of the main drain tile is so low.

However, the reason of poorer drain tile identification by $20 \%$ during two weeks in May 2016 compared to April 2016, , is unclear. These results suggest that even a relatively small change in the soil moisture can play a significant role.

In summer 2016, the drain tiles were above the groundwater level. The soil was drier, although the moisture data show that the change in the soil moisture at the depth of drain tile deposition did not exceed 2\%. Even such small change in moisture, however, was one of the factors causing a significant deterioration in the drain tile identification.

In the autumn of 2016, the drain tiles in plot A were completely under GWL. The flows rates in the drains were very low. Such conditions should be ideal for the drain tile identification. Nevertheless, the results were less successful than in spring. The quality of the recorded radarogram was poor.

The autumn of 2017 brought more success in the drain tile identification in the investigated areas by several percent compared to spring. The quality of the recordings in the radarogram was high. In plot A1, the drain tiles were under or very close to GWL and the flow rate in KP was the lowest for the entire investigated period. The conditions were apparently optimal, with sufficient soil moisture and maximum air content in the drain tiles. This result (these conditions) correspond to the hypothesis. The plot B, however, recorded the lowest GWL for the investigated period. The soil surrounding the drain tiles was driest even by the moisture data, with practically no discharge. The reason why the drain tiles were so well visible even in this plot is unclear.

The hypothesis that the conditions for the best drain tile visibility cannot be unequivocally determined was confirmed by Alred in 2008. These authors attempted to detect the drain tiles at 14 tested areas with differing soil texture. In some areas, their success rate was $100 \%$. Two 
areas brought no results, with the reasons remaining obscure.

The later study by Allred (2013) shows the dependence of the success on the utilized antenna: the antenna parallel to the drain line works best with very wet soils and water-filled drainage pipe (antenna used by us) and the antenna perpendicular to the drain line works best in moderately dry soils and empty, air-filled drainage pipes.

Using the ground penetrating radar, it was possible to successfully identify the drainage system in the experimental locality Dehtáře. The dependence of the measurement results on the season and current hydrological conditions was confirmed. The measurements were performed starting from April until November. The collected data can be summarized in several points:

- The conditions of locality Dehtáře show that the best results are obtained with an antenna of $500 \mathrm{MHz}$ frequency, which provides both sufficient resolution and depth of penetration

- The period immediately after the snowmelt seems the best period for drainage detection because the moisture of soil surrounding the drain tiles is the highest

- An essential role in high soil moisture is played by the groundwater level

- The quantity of the water running through the drain tile is probably not critical if the tile also contains a sufficient quantity of air

- The reason why the drain tiles were well visible in the autumn of 2017 but not in the autumn of 2016 is unclear

- 3D processing and imaging of radarograms is accurate and illustrative, but not practical in large areas due to the high transect density

In following studies, the investigated locality should be extended and further series of measurements should be performed.

\section{Acknowledgements}

This project was supported by the Ministry of Agriculture of the CR, Institutional support MZE RO2019.

\section{REFERENCES}

1. Allred, B.J., Fausey, N.R., Peters, Jr. L., Chen, C., Daniels, J.J., Youn, H. 2004. Detection of buried agricultural drainage pipe with geophysical methods. Applied Engineering in Agriculture, 20(3), 307-318.
2. Allred, B.J., Fausey, N.R., Peters, Jr. L., Chen, C., Daniels, J.J., Youn, H. 2005. Important considerations for locating buried agricultural drainage pipe using ground penetrating radar. Applied Engineering in Agriculture, 21(1), 71-87.

3. Allred, B.J., Daniels, J.J. 2008. Agricultural drainage pipe detection using ground-penetrating radar, Chapter 29 In: Allred BJ, Daniels JJ, Ehsani MR (eds). Handbook of agricultural geophysics. United States: CRC Press Taylor Francis Group, LLC: 363-374.

4. Allred, B.J., Redman, J.D. 2010. Location of agricultural drainage pipes and assessment of agricultural drainage pipe conditions using groundpenetrating radar. Journal of Environmental and Engineering Geophysics, 15(3), 119-134.

5. Allred, B.J. 2013. A GPR agricultural drainage pipe detection case study: Effects of antenna orientation relative to drainage pipe directional trend. Journal of Environmental \& Engineering Geophysics, 18(1), 55-69.

6. Annan, A. P. 2002. GPR - History, Trends, and Future Developments. Subsurface Sensing Technologies and Applications, 3(4), 253-270.

7. Ayala-Cabrera, D., Herrera, M., Izquierdo, J., PérezGarcía, R. 2011. Location of buried plastic pipes using multi-agent support based on GPR images. Journal of Applied Geophysics, 75, 679-686.

8. Daniels, D.J. 2004. Ground penetrating radar: 2nd edition. The Institution of Electrical Engineers: United Kingdom.

9. Jol, Hm. (Ed.). 2009. Ground penetrating radar: Theory and applications. Elsevier: Amsterdam.

10. Karásek, P., Tlapáková, L., Podhrázská, J. 2015. The location and extent of systematic drainage in relation to land use in the past and at present and in relation to soil vulnerability to accelerater infiltration in the Protected Landscape area Železné hory. Acta Universitatis Agriculturae et Silviculturae Mendelianae Brunensis, 63(4), 1121-1131.

11. Kvítek, T. 1985. Water regime and meadow groundbearing capacity after its drainage. Ph.D. thesis. Czech University of Agriculture: Prague.

12. Kulhavý, Z., Doležal, F., Fučík, P., Kulhavý, F., Kvíitek, T., Muzikáŕ, R., Soukup, M., Švihla, V. 2007. Management of agricultural drainage systems in the Czech Republic. Irrigation and Drainage, 56, 141-149.

13. Van Der Kruk, J., Slob, E.C., Fokkema, J.T. 1999. Background of ground-penetrating radar measurements. Geologie en Mijnbouw, 77, 177-188.

14. World Reference Base For Soil Resources. 2006. World Soil Resources Reports 103. Food and Agriculture Organization of the United Nations. Rome.

15. Zajíček, A., Kvítek, T., Kaplická, M., Doležal, F., Kulhavý, Z., Bystřický, V., Žlábek, P. 2011. Drainage water temperature as a basis for verifying drainage runoff composition on slopes. Hydrological Processes, 25, 3204-3214. 